\title{
Sexually transmitted diseases in Sabah and Sarawak
}

\author{
R D CATTERALL \\ From James Pringle House, Middlesex Hospital, London
}

SUMMARY Despite being part of one of the few remaining primitive areas of the world, both Sabah and Sarawak are provided with adequate, though simple, urban and rural general medical services. At present no reliable data on the incidence of sexually transmitted diseases in these areas have been collected and no organised treatment services are available. Gonorrhoea appears to be the commonest notifiable infectious disease in Sarawak, and $\beta$-lactamase-producing strains have been isolated. Because of the rapidly expanding economy and the encouragement of the tourist trade, sexually transmitted disease is likely to prove an increasing problem, for which a specialised service for diagnosis and treatment is badly needed.

\section{Introduction}

Borneo is one of the few remaining primitive areas of the world and conjures up images of deep impenetrable jungle and head hunters. Situated in the East Indies in the South China Sea, it is the fourth largest island in the world. It was first reached by Portuguese discoverers in 1521 and the name Borneo was given to the whole island. Politically it now comprises: Kalimantan, the largest section, which is Indonesian; Sarawak and Sabah, which are part of Malaysia; and Brunei, an independent sultanate under British protection.

Most of Borneo is wild forestclad jungle and mountainous areas reaching 13600 feet at Mount Kinabalu, but there are also wide alluvial plains and winding rivers with low marshy shores and silted estuaries. The population of the interior of the island consists of Dayak tribes, who are animists and former head hunters; they live by the sale of jungle produce, grow rice, and fish in the rivers. The Malays are a later coastal people, who are mostly Moslems and live by agriculture, fishing, and trading. The Chinese originally came because of gold and metal mining but now work as shopkeepers, tradesmen, and farmers. There are a large number of refugees from surrounding countries, and since the discovery of off-shore oil and the intensified exploitation of the forests many foreign workers have come to Borneo.

Address for reprints: Dr R D Catterall, James Pringle House, Middlesex Hospital, London W1

Accepted for publication 2 May 1981

\section{Sabah and Sarawak}

Sabah occupies the north-eastern tip of the island. It is part of the Federation of Malaysia and is roughly the size of Ireland. The climate is tropical with afternoon temperatures of $32^{\circ} \mathrm{C}\left(90^{\circ} \mathrm{F}\right)$ but cool nights of $22^{\circ} \mathrm{C}\left(72^{\circ} \mathrm{F}\right)$. The typhoon belt passes just north of Sabah, which is known as "the land below the wind."

Internal communication is poor and the paved road network is very limited. Other roads are often damaged or washed away by the heavy tropical rains. Most of the travelling between the towns is by the Malaysian airline system, which provides an excellent service using small Fokker Friendship aircraft or even Islanders or Skyvans.

Bahasa Malay is now the official national language with English as the second language. Islam is the official religion. The recorded history of the country is short. At the end of the eighteenth century a large concession of land was obtained on behalf of the East India Company. In 1881 a charter was granted to the British North Borneo Company, which was responsible for the administration of British North Borneo until the Japanese occupation in 1941. After the war the territory was temporarily taken over by the Colonial Office and finally joined the Federal State of Malaysia in 1963.

Sarawak is a much larger territory and occupies most of the north-western coastal area of the island. In addition to the forestclad jungle, the landscape is characterised by a series of serpiginous rivers, which arise in the mountainous area and flow sluggishly through the plain to the sea. The rainfall is very 
heavy, averaging $3000 \mathrm{~mm}$ (120 inches) annually, with a mean relative humidity of about $85 \%$. The temperature rarely exceeds $36 \cdot 5^{\circ} \mathrm{C}\left(97 \cdot 7^{\circ} \mathrm{F}\right)$ but there is little variation throughout the year. Like Sabah the country is sparsely populated, the heaviest concentrations being on the coastal plains and the valleys. In the towns society tends to be multiracial. The family still exerts a strong influence but to a lesser degree than formerly, and there is a steady movement of young people from the country to the towns. Although Bahasa Malay is the language favoured by the government, English is still the main working language in Sarawak.

The modern history of the country is romantic and begins with the landing of James Brooke in 1839. At that time there were many revolts against the Sultan and widespread piracy on the seas. In return for suppressing the revolts and eliminating the pirates, he was installed as Rajah of a large section of the territory. In 1864 Sarawak was recognised by Britain as an independent state and in 1868 James Brooke was succeeded as Rajah by his nephew Charles Brooke. Large areas of territory were added to the Sarawak Raj and it remained the personal domain of the Brooke family until 1941, when the third Rajah, Sir Charles Vyner Brooke, introduced a new con- stitution but was forced to leave because of the $\underline{\underline{ }}$. Japanese invasion. In 1946 he decided that in the best interests of Sarawak's economic future it should come under the British Crown; thus it became a Crown Colony in July 1946. In 1962 a commission, chaired by Lord Cobbold, visited the territories and recommended that both Sabah and Sarawak should become members of the Federation of Malaysia. In September 1963, Sabah and Sarawak each became independent states within the Federation of $\overrightarrow{0}$ Malaysia.

\section{Medical services}

Health and medical care are priorities of both the Federal Government in Kuala Lumpur and of the individual state governments. Doctors work either $\mathrm{\omega}$ for the government or in private practice. The former are employed largely in the hospital service, but they also provide a rural medical service and act as flying doctors to outlying areas. Most general practitioners work in the centre of the cities and, with relative economic affluence in some sections of the community, private practice is increasing in both territories.

There is a director of medical services for both $\stackrel{\infty}{=}$

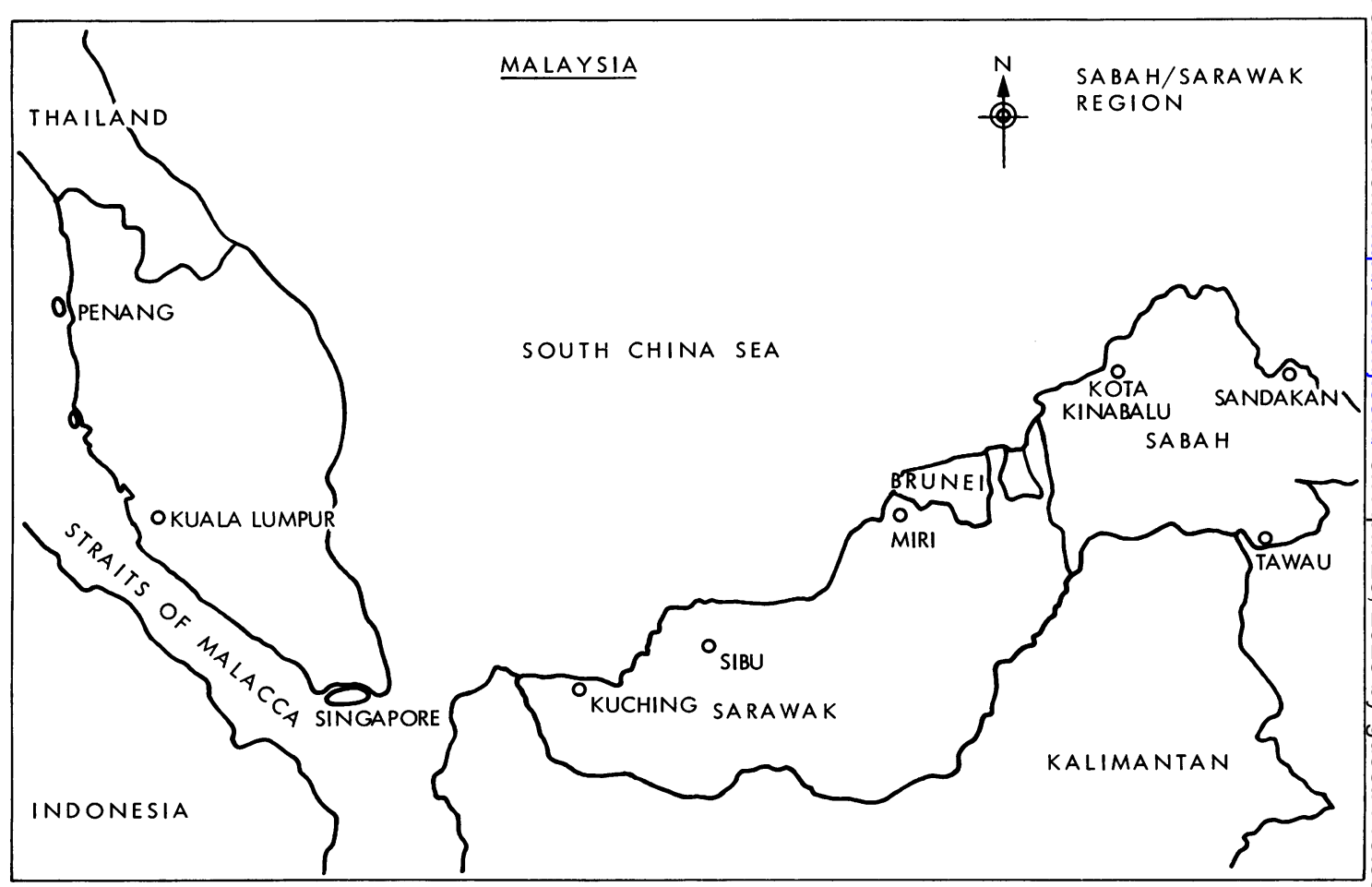

FIGURE Map of Malaysia showing the Sabah and Sarawak regions. 
Sabah and Sarawak and three deputy directors responsible for public health, hospitals, and dental services. In addition there are divisional medical officers and medical officers in charge of district hospitals. Each town has either a district or a divisional hospital. The rural health services are provided in district or community health centres. There are also several travelling dispensaries and floating clinics.

Most of the hospitals were built during the British colonial days and have been well maintained. Some new hospital building is being undertaken and existing buildings are being upgraded. There are three classes of wards in the larger hospitals-firstclass with single beds and comfortable suites, secondclass with four beds in a cubicle, and third-class with open wards of up to 20 beds. Patients pay a modest sum for outpatient or inpatient care.

There is an overall shortage of doctors and nurses. Most hospitals are without a pathologist and biopsy specimens are sent to Kuala Lumpur. It usually takes up to six weeks before reports are available. Many hospitals are without trained physicians and obstetricians and gynaecologists. In many areas the service is maintained by Indian doctors, many of whom come from South India, particularly Kerala. Although the facilities are simple, the equipment is adequate; the persistence of diseases such as cholera, typhoid fever, diphtheria, tuberculosis, and resistant malaria provide excellent experience for young doctors.

\section{Sexually transmitted diseases}

Patients with sexually transmitted diseases (STDs) are treated principally by general practitioners although an unknown number receive traditional tribal, herbal, and mineral remedies. Some cases are diagnosed and treated by hospital doctors, but there are no doctors with specialist knowledge or training in the subject. No figures or statistics are available in Sabah, where there is a tendency to deny that there is a problem.

On one ward round at the Queen Elizabeth Hospital at Kota Kinabalu, however, there were three cases of gonococcal ophthalmia in newborn infants and one case of gonococcal urethritis and ophthalmia in a man. This was not regarded as being exceptional. Subsequent discussion indicated that many doctors were treating cases of undiagnosed STD by giving large doses of broad-spectrum antibiotics, especially ampicillin. Usually there was no follow-up and no attempt at contact tracing.

In Sarawak, on the other hand, an effort is made to encourage reporting of cases, and some figures are available for the past three years. There is obviously gross under-reporting. Nevertheless, in 1979, 3094 cases of gonorrhoea were notified for the whole territory, making gonorrhoea the commonest notifiable infectious disease in a population of nearly $1 \frac{1}{2}$ million people.

As is the case in most developing countries nonspecific urethritis is diagnosed much less frequently than gonorrhoea and the gonorrhoea-to-non-specific urethritis ratio was 7:1 in 1979. The reasons for this difference between developed countries, where nonspecific urethritis is now the commonest sexually communicable disease, and developing countries, where gonorrhoea is diagnosed much more frequently, are not properly understood. Trichomoniasis was commonly diagnosed in women but Candida albicans was very rarely found.

It is probable that strains of gonococci producing $\beta$-lactamase are occurring in both territories, as general practitioners and hospital doctors report treatment failures with ampicillin and penicillin which appear to respond to treatment with kanamycin and spectinomycin. A few of these strains have been isolated and shown to produce $\beta$-lactamase in the department of microbiology at the Sarawak General Hospital, Kuching. The magnitude of the problem and the source of the resistant strains is, however, unknown.

Syphilis was usually diagnosed in the latent stage, but some cases of primary and secondary syphilis were recognised. New cases of late syphilis were rarely recorded and congenital syphilis was believed to be very uncommon. It is surprising that yaws is now hardly ever diagnosed and many of the doctors have never seen an acute case of the disease. It is generally assumed that any patient under the age of 25 years is unlikely to have come into contact with an infectious case, and a diagnosis of yaws in patients under that age is unlikely to be correct, even if they come from the most remote areas of the country.

It is also surprising that very few cases of chancroid, lymphogranuloma venereum, and granuloma inguinale were reported, but the general practitioners said that scabies, pediculosis pubis, and tinea cruris were common.

In a multiracial society with a wide variety of religious beliefs contact tracing presents great problems. It is not the usual practice for doctors to ask to see the sexual contacts, especially if a wife or wives are affected. Men are frequently treated in isolation, and no questions are asked about the source of the infection or about anyone else who may have been infected subsequently. A rising incidence of pelvic inflammatory disease, ectopic pregnancy, and dyspareunia would be expected as a result of this neglect of the interests of women. Both the general practitioners and the hospital doctors agreed that all 
three conditions were now common and appeared to be increasing.

\section{The future}

Rapid and far-reaching economic and social changes are taking place in both Sabah and Sarawak. The discovery of oil, natural gas, and mineral deposits-to say nothing of the enormous reserves of timber-are resulting in a higher standard of living in the towns and along the coastal plains. Traditional family ties and restraints are beginning to be eroded in the towns, and even in the country young people are becoming more mobile and independent of their families. There is an important shift in the population from rural areas to the towns and there are faint hints of changes in the status of women towards greater independence and freedom.

The economic prosperity and the natural wealth have attracted large numbers of foreign workers to exploit the oil, gas, minerals, and timber. Several of the expanding towns, such as Tawau and Sandakan or Sibu and Miri, have all the characteristics of boom towns with a lot of easy money available. They also have the social and medical problems associated with boom towns, not the least of which is a high rate of STD.

The government is actively trying to encourage the tourist trade and in the larger centres new hotels are springing up and amenities for tourists are being developed. Already plane loads of foreign tourists are arriving at the main airports and are taking advantage of the miles of empty sandy beaches or are visiting the wilder interior on river or jungle excursions.

All the social, economic, and medical factors indicate that there is likely to be a great increase in the incidence of the STDs during the next few years. Health is a top government priority, and it is to be hoped that adequate steps will be taken to anticipate this rise in infections before the situation gets out of hand and control becomes impossible.

The first step might be an attempt to define the size of the problem in both Sabah and Sarawak, using modern epidemiological techniques. Obtaining accurate figures will, however, be very difficult $\underline{\square}$. because of the universal problem of under-reporting, $\stackrel{?}{?}$ but estimates of the incidence of the major diseases $\vec{F}$ would enable proper planning to be undertaken.

None of the doctors has had any special training in the diagnosis and treatment of STDs, and most have $\frac{\bar{\sigma}}{\bar{\omega}}$. had little or no teaching of the subject as under- $\overrightarrow{\widehat{D}}$ graduate students. The evidence suggests that most $\varrho$ patients who seek medical advice are treated by general practitioners without the benefit of micro- $\vec{\circ}$ biological or serological tests, although some attend the hospitals and are treated as outpatients. Very few $\vec{\omega}$ patients are admitted to hospital for treatment.

General practitioners, hospital doctors, and medical administrators are concerned about the $-y$ general lack of training and up-to-date knowledge of $\frac{\sigma}{\omega}$ STDs. They are also worried about the possibility of $\mathcal{\omega}$ a great increase in the incidence of STD and the lack 0 of facilities and trained staff to deal with it.

There is general agreement that it would be helpful if one or more of the young hospital doctors could be $\mathbb{D}$ sent to Britain to attend the full-time three-month $\stackrel{\oplus}{\Im}$ course on STD organised by the British Postgraduate $\frac{7}{0}$ Medical Federation and possibly sit the examination for the Diploma in Venereology of the Society of $\overrightarrow{0}$ Apothecaries of London or attend the course for the $\stackrel{\infty}{-}$ Diploma in Venereology organised by the University 0 of Liverpool. Based on experience in Britain, one specialist in STD is required for every half million of the population. Two trained physicians would eventually be required for Sabah and three for Sarawak. Specially selected nurses might also be sent to Britain to take part in the six-month post-basic 0 course on STD organised by the Royal College of Nursing at several teaching hospitals in Britain.

Once adequately trained staff are available $a \stackrel{\circ}{=}$ model clinic for patients with STD might be $\stackrel{\text { s }}{=}$ established in the outpatient department of a large hospital at Kota Kinabalu and Kuching. These clinics would establish standards of investigation, treat- $\delta$ ment, and follow-up, develop the contact tracing service, provide facilities for research, act as centres 옥 for postgraduate teaching, and offer facilities for the $>$ referral of difficult cases. They would also help with the training of medical auxiliaries to work in the $N$ rural, district, and community health centres. 